ISSN : 2580-3220, E-ISSN : 2580-4588

J. Mandiri., Vol. 4, No. 2, Desember 2020 (192 - 198)

(C)2018 Lembaga Kajian Demokrasi

dan Pemberdayaan Masyarakat (LKD-PM)

DOI : https://doi.org/10.33753/mandiri.v4i2.142

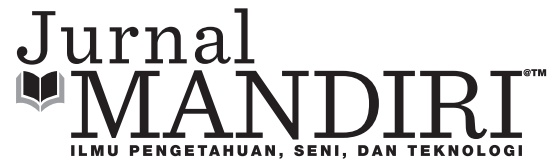

\title{
Pengaruh Promosi Go-Pay Terhadap Keputusan Pengguna Aplikasi Transportasi Online di Ruang Lingkup Universitas Pamulang (Studi Kasus Mahasiswa Prodi Manajemen)
}

\author{
Hadijah Febriana \\ Fakultas Ekonomi, Universitas Pamulang \\ dosen02182@unpam.ac.id \\ Intan Sari Budhiarjo \\ Fakultas Ekonomi, Universitas Pamulang \\ dosen02128@unpam.ac.id
}

\begin{abstract}
Abstrak
Penelitian ini bertujuan untuk mengetahui pengaruh promosi Go-pay terhadap keputusan pengguna aplikasi transportasi online di ruang lingkup Universitas Pamulang. Metode penelitian yang digunakan adalah metode penelitian kuantitatif. Populasi dalam penelitian ini adalah mahasiswa/mahasiswi semester 7 prodi manajemen Universitas Pamulang. Sampel dalam penelitian ini adalah 200 responden yang terdapat dalam populasi. Metode analisis yang digunakan adalah analisis kuantitatif. Secara parsial promosi Go-pay (x) memiliki $t_{\text {hitung }}$ sebesar 11,966y $>t_{\text {tabel }} 1,65259$ dengan nilai signifikan 0,00 maka dapat disimpulkan promosi Go-pay berpengaruh positif dan signifikan terhadap keputusan pengguna. Berdasarkan hasil uji koefisien determinasi ( $R$ square) menunjukkan angka 0,420 artinya hubungan promosi Go-pay dengan keputusan pengguna sebesar 42\%, sedangkan sisanya 58\% dipengaruhi oleh variabel lain yang tidak diteliti dalam penelitian ini. Promosi berpengaruh secara positif dan signifikan terhadap keputusan pengguna Go-pay dalam menggunakan trasnportasi online di Universitas Pamulang. Artinya semakin tinggi dan semakin bervariasi promosi yang ditawarkan oleh pihak perusahaan, maka semakin besar peluang pengguna memutuskan untuk menggunakan jasa transportasi online khususnya di Universitas Pamulang.
\end{abstract}

Kata Kunci : Promosi, Go-Pay, Keputusan Pengguna

\begin{abstract}
Research purposes This study aims to determine the effect of go-pay promotion on the decisions of users of online transportation applications within the scope of the University of Pamulang. The research method used is quantitative research methods. The population in this study were students of the 7 th semester of the Pamulang University management study program. The sample in this study were 200 respondents in the population. The analytical method used is quantitative analysis. Partially Go-pay promotion variable $(x)$ has a $t_{\text {count }}$ of 11.966 $>t_{\text {table }} 1.65259$ with a significant value of 0.00 , it can be concluded that Go-pay promotion has a positive and significant effect on user decisions. Based on the test results the coefficient of determination (R square) shows the number 0.420 which means that the relationship between Go-pay promotion and user decision is $42 \%$, while the remaining 58\% is influenced by other variables not examined in this study. Promotion has a positive and significant effect on Go-pay users' decisions to use online transportation at Pamulang University. This means that the higher and more varied the promotions offered by the company, the greater the chance for users to decide to use online transportation services, especially at Pamulang University.
\end{abstract}

Keywords : Promotion, Go-Pay, User Decision 


\section{PENDAHULUAN}

Berkembangnya internet di tengah-tengah pertumbuhan penduduk yang begitu pesat menjadikan internet sangat dibutuhkan untuk memenuhi kebutuhan masyarakat. Jasa transportasi berbasis aplikasi online yang menggunakan internet sangat berpengaruh bagi masyarakat dalam segala aktivitas agar efektif dan efisien. Salah satu bisnis yang sedang berkembang saat ini adalah Gojek. Perusahaan ini merupakan salah satu yang terbesar di bidang transportasi di Indonesia yang menggunakan pelayanan online. Hal ini dapat dilihat pada tabel 1 di bawah ini:

\begin{tabular}{|c|c|c|}
\hline \multicolumn{3}{|c|}{ Tabel 1. Data Pengunduh Aplikasi Transportasi Online } \\
\hline No & Nama & Jumlah \\
\hline 1. & Gojek & 100 Juta \\
\hline \multicolumn{3}{|c|}{ Keterangan: Berdasarkan pengguna aplikasi. Sumber: Play Store, 2019} \\
\hline
\end{tabular}

Dengan adanya aplikasi Gojek ini, akan mempermudah konsumen untuk melakukan pemesanan secara langsung dengan menu yang tersedia pada aplikasi. Adapun produk Gojek yang ditawarkan melalui menunya yaitu GoRide, GoCar, GoFood, GoBluebird, GoSend, GoPulsa, GoPoint, GoBills, GoShop, GoMart, GoBox, GoMassage, GoDaily, GoClean, GoFix, GoLaundry, GoGlam, GoTix, Go Auto, GoMed, GoGemes, dan GoPlay. Konsumen yang menggunakan aplikasi Gojek akan mencari keuntungan yang dapat dirasakan secara langsung. Gojek pun meemberikan promo menarik dari mulai diskon, voucher cashback atau cashback. Berikut promo Go-Pay pada Agustus 2019:

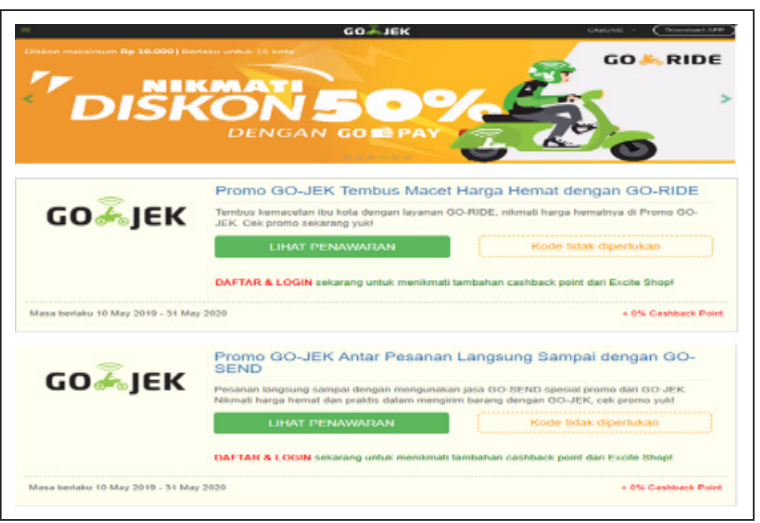

Gambar 1. Promo Go-Pay, Agustus 2019
Hasil penelitian Danang Kukuh Argitama dan Sri Suryoko (2020) menunjukkan bahwa promosi berpengaruh terhadap keputusan pengguna Go-Pay di Kota Semarang. Amalia Fajrin (2020) dalam penelitiannya menyimpulkan bahwa promosi penjualan berpengaruh positif terhadap keputusan penggunaan. Hasil berbeda diperoleh Fitriani Latief dan Dirwan (2020) yang menyatakan bahwa aktivitas promosi tidak signifikan memengaruhi keputusan penggunaan.

Berdasarkan teori dan beberapa penelitian terdahulu maka tujuan penelitian ini adalah untuk mengetahui Pengaruh Promosi Go-Pay Terhadap Keputusan Pengguna Aplikasi Transportasi Online di Ruang Lingkup Universitas Pamulang (Studi Kasus Mahasiswa Prodi Manajemen).

\section{METODE}

Penelitian ini menggunakan metode penelitian kuantitatif yang bersifat deskriptif. Dengan metode kuantitatif, akan diperoleh signifikansi perbedaan kelompok atau signifikansi hubungan antar variabel yang diteliti. Populasi dalam penelitian ini adalah pihak-pihak yang berhubungan secara langsung dengan kegiatan penggunaan aplikasi ojek online di ruang lingkup Universitas Pamulang, khususnya mahasiswa/mahasiswi prodi manajemen Universitas Pamulang.

Pengambilan sampel pada penelitian ini menggunakan teknik Purposive Sampling. Metode Purposive Sampling di mana sampel diambil dengan berdasarkan pertimbangan subyektif peneliti. Persyaratan yang dibuat sebagai kriteria harus dipenuhi sebagai sampel. Jadi dasar pertimbangannya ditentukan tersendiri oleh peneliti. Selanjutnya sampel yang diambil secara Purposive Sampling oleh peneliti harus mahasiswa aktif jurusan Manajemen (semester 7) dan mahasiswa jurusan manajemen yang menggunakan jasa angkutan ojek online minimal dua kali.

Dikarenakan jumlah populasi yang terlalu besar yaitu lebih dari 2.000 orang dan keterbatasan waktu, serta tenaga yang dimiliki, maka jumlah sampel yang diambil sebanyak 200 orang yang terdapat dalam populasi tersebut. Menurut Arikunto (2013: 62), "Untuk sekedar ancer-ancer 
maka apabila subyeknya kurang dari 100, lebih baik diambil semua sehingga penelitiannya merupakan penelitian populasi”.

Selanjutnya jika jumlah subyeknya besar dapat diambil 10\%-15\% atau 20\%-25\% atau lebih. Pengumpulan data primer dilakukan dengan caracara sebagai berikut: kuesioner, observasi dan kepustakaan. Data sekunder pada penelitian ini diperoleh dari studi pustaka melalui buku, jurnal, artikel, situs internet, dan literatur-literatur lain yang berhubungan dengan permasalahan dalam penelitian ini.

Metode analisis yang digunakan dalam penelitian adalah statistik deskriptif, uji validitas, uji reliabilitas, uji asumsi klasik, analisis koefisien determinasi $\left(\mathrm{R}^{2}\right)$, dan uji hipotesis secara parsial (uji t). Variabel penelitian adalah suatu artibut atau sifat atau nilai dari orang, atau kegiatan yang mempunyai variasi tertentu yang diterapkan oleh peneliti untuk dipelajari dan ditarik kesimpulannya (Sugiyono, 2012:59).

\begin{tabular}{|c|c|c|}
\hline \multicolumn{3}{|c|}{ Tabel 2. Operasional Variabel Penelitian } \\
\hline Variabel & Definisi & Indikator \\
\hline $\begin{array}{l}\text { Promosi }\left(X_{1}\right) \\
\text { Philip Kotler } \\
\text { (2005:249) }\end{array}$ & $\begin{array}{l}\text { Unsur bauran pemasaran komunikasi } \\
\text { persuasif perusahaan yang di } \\
\text { daya gunakan untuk memberikan, } \\
\text { membujuk dan meningkatkan tentang } \\
\text { produk perusahaan untuk menarik } \\
\text { konsumen membeli produknya }\end{array}$ & $\begin{array}{l}\text { 1. Personal Selling } \\
\text { 2. Advertising } \\
\text { 3. Sales Promotion } \\
\text { 4. Direct Marketing } \\
\text { 5. Public Relation }\end{array}$ \\
\hline $\begin{array}{l}\text { Keputusan } \\
\text { Pembelian } \\
\text { (Y) } \\
\text { Kotler dan } \\
\text { Armstrong } \\
\text { (2008:179) }\end{array}$ & $\begin{array}{l}\text { Sebagai suatu proses dimana } \\
\text { konsumen mengenali kebutuhannya, } \\
\text { mencari informasi mengenai } \\
\text { prroduk yang sesuai dan mengambil } \\
\text { keputusan tentang produk mana yang } \\
\text { akan dibeli atau digunakan }\end{array}$ & $\begin{array}{l}\text { 1. Pengenalan Masalah } \\
\text { 2. Pencarian Informasi } \\
\text { 3. Evaluasi Alternatif } \\
\text { 4. Keputusan Pembelian } \\
\text { 5. Perilaku Pasca } \\
\text { Pembelian }\end{array}$ \\
\hline
\end{tabular}

\section{HASIL dan PEMBAHASAN}

\section{Karakteristik Data Responden}

Responden dalam penelitian ini adalah konsumen yang pernah menggunakan jasa angkutan ojek online minimal dua kali. Dari seluruh jumlah kuesioner diperoleh 200 kuesioner yang digunakan untuk analisis data. Sedangkan untuk karakteristik responden itu sendiri terdiri dari jenis kelamin dan usia responden yang berpartisipasi dalam penelitian ini. Karakteristik dari masing-masing responden dapat dilihat dalam tabel-tabel berikut:

\begin{tabular}{|c|c|c|c|}
\hline \multicolumn{4}{|c|}{ Tabel 3. Jenis Kelamin Responden } \\
\hline No. & Jenis Kelamin & Total & Persentase \\
\hline 1 & Laki-Laki & 78 & $39 \%$ \\
\hline 2 & Perempuan & 122 & $61 \%$ \\
\hline \multicolumn{2}{|c|}{ Total } & 200 & $100 \%$ \\
\hline \multicolumn{2}{|c|}{ Sumber: Data diolah dari kuesioner, 2020 } \\
\hline
\end{tabular}

Dari tabel di atas dapat dijelaskan bahwa untuk responden berjenis kelamin laki-laki sebanyak 78 orang dari total 200 responden atau sebesar 39\% dari total responden. Sedangkan untuk responden berjenis kelamin perempuan sebanyak 122 orang dari total 200 responden atau sebesar $61 \%$ dari seluruh total responden.

Jenis kelamin responden dominan yaitu pada kelompok perempuan sebesar 122 orang (61\%). Dikutip dari detik.com (2017), pembedahan dari jenis kelamin konsumen, pengguna Gojek berasal dari perempuan dengan mendominasi $69 \%$ dan laki-laki 31\%. Transportasi online mempunyai sisi kenyamanan dan keamanan bagi perempuan.

\begin{tabular}{|c|c|c|c|}
\hline \multicolumn{4}{|c|}{ Tabel 4. Usia Responden } \\
\hline No. & Jenis Kelamin & Total & Persentase \\
\hline 1 & 18-25 Tahun & 188 & $94 \%$ \\
\hline 2 & 26-35 Tahun & 11 & $5,5 \%$ \\
\hline 3 & 36-45 Tahun & 1 & $0,5 \%$ \\
\hline 4 & $>45$ Tahun & 0 & 0 \\
\hline & Total & 200 & $100 \%$ \\
\hline \multicolumn{2}{|c}{} & \multicolumn{2}{c|}{ Sumber: Data diolah dari kuesioner, 2020 } \\
\hline
\end{tabular}

Berdasarkan tabel di atas dapat diuraikan untuk responden dari kelompok usia 18-25 tahun sebanyak 188 atau sekitar 94\%. Untuk tingkat usia 26-35 tahun sebanyak 11 orang atau sekitar 5,5\%. Untuk tingkat usia 36-45 tahun sebanyak 1 atau sekitar $0,5 \%$. Untuk tingkat usia $>45$ tahun sebanyak 0 orang. Hal ini berarti dari 200 orang responden, tidak ada yang berusia lebih dari 45 tahun dari keseluruhan responden.

Umur responden dominan yaitu pada kelompok umur 18-25 tahun (94\%). Kelompok umur tersebut merupakan generasi milenial yang tumbuh dewasa bersama perkembangan teknologi sehingga individu pada kelompok umur tersebut telah akrab dengan digital. 


\section{Uji Validitas dan Reliabilitas}

\section{Uji Validitas}

Untuk mengolah uji validitas, peneliti menggunakan program SPSS versi 25. Menurut Sugiyono (2015:178), syarat minimum suatu item dianggap valid dengan kriteria yaitu jika Cronbach Alpha $>0,30$ maka instrumen valid dan jika Cronbach Alpha< 0,30 maka instrumen tidak valid.

\begin{tabular}{|c|c|c|c|c|c|}
\hline \multicolumn{6}{|c|}{$\begin{array}{l}\text { Tabel 5. Uji Validitas Promosi Go-Pay Terhadap } \\
\text { Keputusan Pengguna Aplikasi Transportasi Online }\end{array}$} \\
\hline Variabel & Indikator & Item & $\begin{array}{c}\text { Cronbach } \\
\text { Alpha } \\
\text { (Go-pay) }\end{array}$ & $\begin{array}{c}\text { Standar } \\
\text { Cronbach } \\
\text { Alpha } \\
\text { IGo-pay }\end{array}$ & Hasil Uji \\
\hline \multirow{15}{*}{$\begin{array}{l}\text { Promosi } \\
\qquad(X)\end{array}$} & \multirow{3}{*}{$\begin{array}{l}\text { Personal } \\
\text { Selling }\end{array}$} & 1 & 0.891 & 0,30 & Valid \\
\hline & & 2 & 0.898 & 0,30 & Valid \\
\hline & & 3 & 0.883 & 0,30 & Valid \\
\hline & \multirow{3}{*}{ Advertising } & 1 & 0.879 & 0,30 & Valid \\
\hline & & 2 & 0.885 & 0,30 & Valid \\
\hline & & 3 & 0.877 & 0,30 & Valid \\
\hline & \multirow{3}{*}{$\begin{array}{c}\text { Sales } \\
\text { Promotion }\end{array}$} & 1 & 0.885 & 0,30 & Valid \\
\hline & & 2 & 0.884 & 0,30 & Valid \\
\hline & & 3 & 0.885 & 0,30 & Valid \\
\hline & \multirow{3}{*}{$\begin{array}{l}\text { Direct } \\
\text { Marketing }\end{array}$} & 1 & 0.882 & 0,30 & Valid \\
\hline & & 2 & 0.880 & 0,30 & Valid \\
\hline & & 3 & 0.874 & 0,30 & Valid \\
\hline & \multirow{3}{*}{$\begin{array}{l}\text { Public } \\
\text { Relation }\end{array}$} & 1 & 0.878 & 0,30 & Valid \\
\hline & & 2 & 0.879 & 0,30 & Valid \\
\hline & & 3 & 0.883 & 0,30 & Valid \\
\hline \multirow{23}{*}{$\begin{array}{l}\text { Kepu- } \\
\text { tusan } \\
\text { Peng- } \\
\text { guna (Y) }\end{array}$} & \multirow{4}{*}{$\begin{array}{l}\text { Pengenalan } \\
\text { Masalah }\end{array}$} & 1 & 0.916 & 0,30 & Valid \\
\hline & & 2 & 0.920 & 0,30 & Valid \\
\hline & & 3 & 0.919 & 0,30 & Valid \\
\hline & & 4 & 0.916 & 0,30 & Valid \\
\hline & \multirow{5}{*}{$\begin{array}{l}\text { Pencarian } \\
\text { Informasi }\end{array}$} & 1 & 0.915 & 0,30 & Valid \\
\hline & & 2 & 0.915 & 0,30 & Valid \\
\hline & & 3 & 0.911 & 0,30 & Valid \\
\hline & & 4 & 0.913 & 0,30 & Valid \\
\hline & & 5 & 0.915 & 0,30 & Valid \\
\hline & \multirow{5}{*}{$\begin{array}{l}\text { Evaluasi } \\
\text { Alternatif }\end{array}$} & 1 & 0.912 & 0,30 & Valid \\
\hline & & 2 & 0.914 & 0,30 & Valid \\
\hline & & 3 & 0.913 & 0,30 & Valid \\
\hline & & 4 & 0.913 & 0,30 & Valid \\
\hline & & 5 & 0.911 & 0,30 & Valid \\
\hline & \multirow{5}{*}{$\begin{array}{l}\text { Keputusan } \\
\text { Pembelian }\end{array}$} & 1 & 0.912 & 0,30 & Valid \\
\hline & & 2 & 0.911 & 0,30 & Valid \\
\hline & & 3 & 0.913 & 0,30 & Valid \\
\hline & & 4 & 0.912 & 0,30 & Valid \\
\hline & & 5 & 0.913 & 0,30 & Valid \\
\hline & \multirow{4}{*}{$\begin{array}{l}\text { Perilaku } \\
\text { Pasca } \\
\text { Pembelian }\end{array}$} & 1 & 0.913 & 0,30 & Valid \\
\hline & & 2 & 0.915 & 0,30 & Valid \\
\hline & & 3 & 0.921 & 0,30 & Valid \\
\hline & & 4 & 0.920 & 0,30 & Valid \\
\hline & & & Sun & a diolah den & SS 25, 2020 \\
\hline
\end{tabular}

Berdasarkan tabel di atas, menunjukkan bahwa variabel promosi $(\mathrm{X})$ dan keputusan pengguna aplikasi transportasi online $(\mathrm{Y})$ memiliki kriteria valid untuk semua item kuesioner. Diperoleh nilai Cronbach Alpha lebih besar 0,30. Dengan demikian maka semua item kuesioner dinyatakan valid. Untuk itu kuesioner yang digunakan layak untuk diolah sebagai data penelitian.

\section{Uji Reliabilitas}

Menurut Imam Ghozali (2016:88), pengujian reliabilitas suatu variabel penelitian dikatakan reliabel apabila memenuhi kriteria yaitu jika Cronbach Alpha> 0,60 maka instrumen reliabel dan jika Cronbach Alpha< 0,60 maka instrumen tidak reliabel. Hasil uji reliabilitas dalam penelitian ini dilakukan dengan menggunakan software SPSS versi 25.

\begin{tabular}{|c|c|c|c|c|}
\hline \multicolumn{5}{c|}{ Tabel 6. Hasil Uji Reliabilitas } \\
No. & Variabel & Cronbach Alpha & $\begin{array}{c}\text { Standar } \\
\text { Cronbch Alpha }\end{array}$ & Ket \\
\hline 1 & Promosi Go-pay $(X)$ & 0,890 & 0,60 & Reliabel \\
\hline 2 & Pengguna Go-pay $(Y)$ & 0,934 & 0,60 & Reliabel \\
\hline \multicolumn{5}{|c|}{ Sumber: Data primer diolah, 2020 } \\
\hline
\end{tabular}

Berdasarkan hasil uji reliabilitas pada tabel di atas, dapat diketahui bahwa seluruh variabel yang digunakan dinyatakan reliabel. Sebab hasil Cronbach Alpha lebih besar dari standar Cronbach Alpha.

\section{Uji Asumsi Klasik} Uji Normalitas

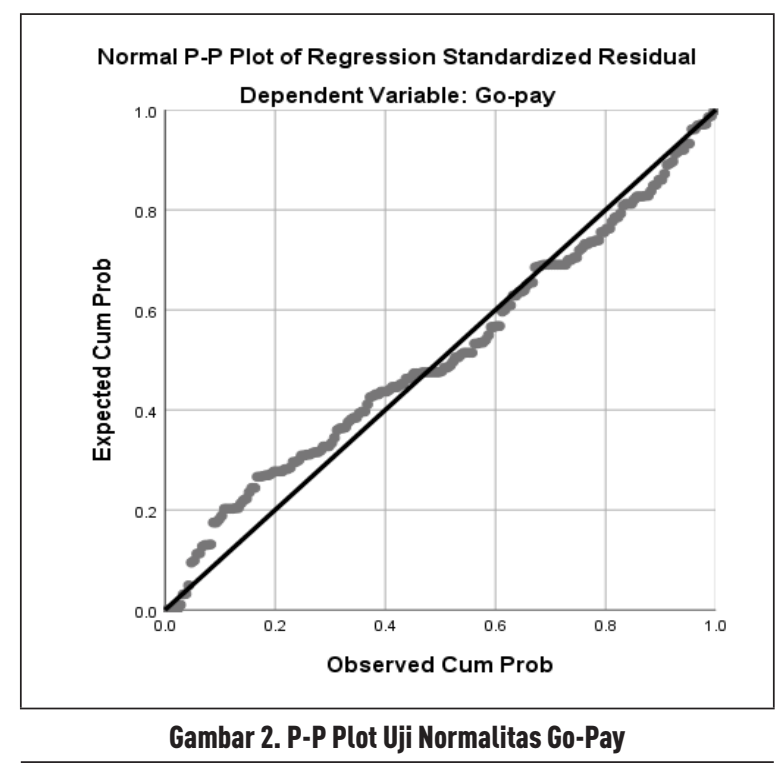


Diagram Penyebaran Titik Residual pada gambar diatas, dapat dilihat bahwa grafik normal probability plot menunjukkan pola grafik yang normal. Hal ini terlihat dari titik-titik yang menyebar di sekitar grafik normal dengan titiktitik yang menyebar di sekitar garis diagonal. Dengan penyebaran yang mengikuti alur garis diagonal tersebut, maka dapat disimpulkan bahwa model regresi layak dipakai karena memenuhi asumsi normalitas.

\section{Uji Multikolinearitas}

\begin{tabular}{|c|c|c|c|}
\hline \multicolumn{4}{|c|}{ Tabel 7. Hasil Uji Multikolinearitas } \\
\hline \multicolumn{4}{|c|}{ Coefficients ${ }^{\mathrm{a}}$} \\
\hline \multirow{2}{*}{\multicolumn{2}{|c|}{ Model }} & \multicolumn{2}{|c|}{ Collinearity Statistics } \\
\hline & & Tolerance & VIF \\
\hline \multirow[b]{2}{*}{1} & (Constant) & & \\
\hline & $\begin{array}{l}\text { Promosi } \\
\text { Go-pay }\end{array}$ & 1.000 & 1.000 \\
\hline \multicolumn{4}{|c|}{ a. Dependent Variable: Keputusan Pengguna Go-pay } \\
\hline \multicolumn{4}{|c|}{ Sumber: data diolah dengan SPSS 25,2020} \\
\hline
\end{tabular}

Hasil uji multikolinearitas dilakukan dengan menggunakan SPSS versi 25. Berdasarkan hasil output yang telah diolah pada SPSS 25 diketahui nilai tolerance pada variabel independen atau variabel $\mathrm{X}$, di mana dalam penelitian ini promosi Go-Pay yakni 1,000 lebih besar dari 0,10. Sementara itu nilai VIF pada variabel promosi Go-Pay sebesar 1,000 atau lebih kecil dari 10,00 sehingga dalam penelitian ini dapat disimpulkan bahwa tidak terjadi multikolineritas.

\section{Uji Heteroskedastisitas}

Berdasarkan hasil output yang telah diolah pada SPSS 25 diketahui bahwa titik-titik pada grafik Scatterplot mempunyai pola penyebaran yang jelas. Titik-titik tersebut menyebar di atas dan di bawah angka 0 pada sumbu Y. Dengan demikian hal ini menunjukkan tidak terdapat gangguan heteroskedastisitas.

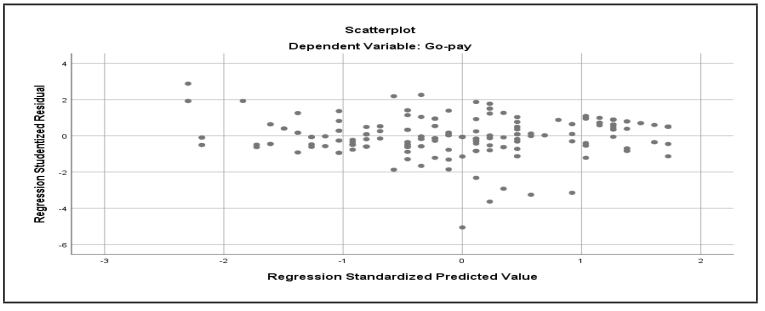

Gambar 3. Scatterplot Uji Heteroskedastisitas Go-pay
Uji Autokorelasi

\begin{tabular}{|c|c|c|c|c|c|}
\hline \multicolumn{6}{|c|}{ Model Summary } \\
\hline Model & $\mathrm{R}$ & R Square & $\begin{array}{l}\text { Adjusted } \\
\text { R Square }\end{array}$ & $\begin{array}{l}\text { Std. Error } \\
\text { of the } \\
\text { Estimate }\end{array}$ & $\begin{array}{l}\text { Durbin- } \\
\text { Watson }\end{array}$ \\
\hline 1 & $.648^{\mathrm{a}}$ & .420 & . 417 & 7.41948 & 2.062 \\
\hline \multicolumn{6}{|c|}{$\begin{array}{l}\text { a. Predictors: (Constant), Promosi Go-pay } \\
\text { b. Dependent Variable: Keputusan Pengguna Go-pay }\end{array}$} \\
\hline
\end{tabular}

Dari tabel di atas diperoleh nilai DurbinWatson sebesar 2,062. Tabel DW dengan signifikansi 0,05 dan jumlah data $(\mathrm{n})=200$, serta $\mathrm{k}=1$ ( $\mathrm{k}$ adalah jumlah variabel independen) diperoleh nilai dl sebesar 1,7071 dan du sebesar 1,8306. Karena nilai DW 2,062 berada pada syarat du $<$ dw $<4-$ du atau $1,7071<2,062<4-1,8306(2,1694)$. Jadi dapat disimpulkan $\mathrm{H}_{0}$ diterima, artinya tidak terjadi autokorelasi positif maupun negatif.

\section{Uji Koefisien Determinasi}

Selanjutnya, output SPSS 25, tabel di bawah ini adalah hasil dari uji determinasi:

Tabel 9. Hasil Uji Koefisien Determinasi ( $\left.R^{2}\right)$ Go-Pay

\begin{tabular}{|c|c|c|c|c|}
\hline \multicolumn{5}{|c|}{ Model Summary } \\
\hline Model & $\mathbf{R}$ & R Square & $\begin{array}{c}\text { Adjusted R } \\
\text { Square }\end{array}$ & $\begin{array}{c}\text { Std. Error } \\
\text { of the Estimate }\end{array}$ \\
\hline 1 & $.648^{\mathrm{a}}$ & .420 & .417 & 7.41948 \\
\hline $\begin{array}{l}\text { a. Predictors: (Constant), Promosi Go-pay } \\
\text { b. Dependent Variable: Keputusan Pengguna Go-pay }\end{array}$ \\
\hline \multicolumn{5}{|c|}{ Sumber: data diolah dengan SPSS 25, 2020 } \\
\hline
\end{tabular}

Nilai koefisien determinasi $\left(\mathrm{R}^{2}\right)$ yang ditentukan dengan $R$ square sebesar 0,420 (yakni pengkuadratan dari koefisien korelasi atau $\mathrm{R}$, yaitu $0,648 \times 0,648=0,420$ ) atau sama dengan sebesar 42 yang di mana dari nilai ini menunjukkan bahwa hubungan variabel bebas dengan variabel terikat sebesar $42 \%$, sisanya $(100 \%-42 \%=58 \%)$ dipengaruhi oleh variabel lain yang tidak diteliti dalam penelitian ini. Variabel lainnya diduga karena potongan harga atau cashback yang ditawarkan jika bertransaksi menggunakan Go-Pay terlalu kecil atau adanya syarat dan ketentuan yang berlaku untuk mendapatkan potongan harga. Hal ini bertolak belakang dengan pesaing seperti Ovo atau GrabPay yang memberikan potongan harga yang lebih besar, sehingga hal ini dapat berpengaruh terhadap keputusan pengguna aplikasi Gojek. 


\begin{tabular}{|c|c|c|c|c|c|c|}
\hline \multicolumn{7}{|c|}{$\begin{array}{l}\text { Tabel 10. Hasil Uji Signifikan Parsial (Uji Statistik t) Go-Pay } \\
\qquad \text { Coefficients }^{\mathrm{a}}\end{array}$} \\
\hline \multirow{2}{*}{\multicolumn{2}{|c|}{ Model }} & \multicolumn{2}{|c|}{$\begin{array}{l}\text { Unstandardized } \\
\text { Coefficients }\end{array}$} & \multicolumn{3}{|c|}{ Standardized Coefficients } \\
\hline & & B & $\begin{array}{l}\text { Std. } \\
\text { Error }\end{array}$ & Beta & $\mathrm{t}$ & Sig. \\
\hline \multirow[b]{2}{*}{1} & (Constant) & 17.022 & 3.667 & & 4.641 & .000 \\
\hline & $\begin{array}{l}\text { Promosi } \\
\text { Go-pay }\end{array}$ & .724 & .061 & .648 & 11.966 & .000 \\
\hline \multicolumn{7}{|c|}{ a. Dependent Variable: Keputusan Pengguna Go-pay } \\
\hline \multicolumn{7}{|c|}{ Sumber: data diolah dengan SPSS 25,2020} \\
\hline
\end{tabular}

Berdasarkan tabel di atas, dapat disimpulkan hasil pengujian variabel bebas dalam hal ini promosi Go-Pay memiliki arti bahwa variabel promosi Go-Pay (X) menunjukkan nilai $\mathrm{t}_{\text {hitung }}$ lebih besar dari $t_{\text {tabel }}(11,966>1.65259)$ atau sig $<\alpha$ $(0,00<0,05)$. Berarti variabel promosi Go-Pay berpengaruh positif dan signifikan terhadap variabel keputusan pengguna. Hasil penelitian ini didukung oleh Dony Indra Permana (2017), yang membuktikan bahwa promosi berdampak positif terhadap peningkatan keputusan pembelian. Hasil penelitian ini juga didukung oleh penelitian Mia Andika Sari dkk (2018), yang membuktikan bahwa daya tarik promosi berpengaruh secara parsial terhadap minat penggunaan $e$-wallet produk Go-Pay dan LinkAja di wilayah Jabodetabek.

\section{SIMPULAN}

Mengacu pada hasil penelitian maka dapat disimpulkan bahwa promosi Go-Pay memiliki pengaruh positif dan signifikan terhadap keputusan pengguna aplikasi transportasi online di ruang lingkup Universitas Pamulang. Adapun keterbatasan yang ada dalam penelitian ini adalah penelitian hanya mencakup mahasiswa/mahasiswi semester 7 prodi manajemen di Universitas Pamulang, Dengan demikian hasil penelitian ini tidak dapat digeneralisasikan secara lebih luas.

Pemilik Gojek disarankan untuk terus berinovasi. Seperti untuk metode pembayaran GoPay (Gojek) perlu terus berinovasi promosi-promosi yang sudah ada. Khususnya dalam hal indicator marketing mix agar konsumen semakin hari tertarik menggunakan jasa Gojek.

\section{PENGHARGAAN}

Sehubungan dengan selesainya penelitian ini, ucapan terima kasih disampaikan kepada Dr. (H.C) Drs. H. Darsono, selaku Ketua Yayasan Sasmita Jaya, Dr. H. Dayat Hidayat, M.M., selaku Rektor Universitas Pamulang, Dr. H. Endang Ruhiyat, S.E., M.M., CSRA, CMA., selaku Dekan Fakultas Ekonomi Universitas Pamulang, dan Dr. Kasmad, S.E., M.M., selaku Ketua Program Studi Mananejem S1 yang senantiasa sabar memberikan pengarahan. Selain itu juga kepada segenap Civitas Akademika Universitas Pamulang, yang telah membantu dalam menyelesaikan penelitian ini di Universitas Pamulang. Semua pihak yang telah membantu kelancaran penelitian ini yang tidak bisa disebutkan satu per satu. Terima kasih atas dorongan, motivasi, bantuan, dan doa yang telah diberikan.

\section{DAFTAR PUSTAKA}

Ali, Hasan. (2013). Marketing dan Kasus-Kasus Pilihan. Yogyakarta: CAPS (Center For Academic Publishing Service).

Alo, Liliweri. (2011). Komunikasi Antar Personal. Jakarta: Remaja Rosdakarya.

Amirullah. (2015). Pengantar Manajemen. Jakarta: Mitra Wacana Media.

Argitama, D.K dan Sri Suryoko (2020). Pengaruh E-Service Quality dan Promosi Terhadap Keputusan Penggunaan Produk Go-Pay (Studi Pengguna Aplikasi Gojek Di Kota Semarang). FISIP Universitas Diponegoro.

Arikunto, S. (2010). Prosedur Penelitian Suatu Pendekatan Praktik. Jakarta: Rineka Cipta. (2013). Prosedur Penelitian: Suatu Pendekatan Praktik. Jakarta: Rineka Cipta.

Arikunto, Suharsimi. (2015). Dasar-dasar Evaluasi Pendidikan. Jakarta: Bumi Aksara.

Asosiasi Penyelenggara Jasa Internet Indonesia (APJJI). https://www.apjii.or.id. Diakses tanggal 23 April 2020 Pukul 20.38.

Cannon, Joseph P., William D. Perreault Jr. dan Jerome McCarthy. (2008). Alih Bahasa : Diana Angelica dan Ria Cahyani. Dasar-Dasar Pemasaran: Pendekatan Manajerial Global. Buku 2. Edisi 16. Jakarta: Salemba Empat. 
Fajrin, Amalia. (2020). Pengaruh Promosi Penjualan dan E-Service Quality Terhadap Keputusan Penggunaan Aplikasi Ovo. Jurnal Riset Manajemen Sains Indonesia (JRMSI) Vol 11, No.2.

GO-JEK, "Tentang Gojek", diakses dari https:// www.go-jek.com/about/ Pada tanggal 20 April 2020 Pukul 03.32.

Ghozali, Imam. (2010). Aplikasi Analisis Multivariate Dengan Program SPSS. Edisi Keempat. Semarang: Badan Penerbit Universitas Diponegoro.

. (2011). Aplikasi Analisis Multivariate

Dengan Program SPSS. Semarang: Badan Penerbit Universitas Diponegoro. . (2013).Aplikasi Analisis Multivariate dengan Program IBM SPSS 21 Update PLS Regresi. Semarang: Badan Penerbit Universitas Diponegoro.

. (2016). Aplikasi Analisis Multivariate dengan Program IBM spss 23. Semarang: Badan Penerbit Universitas Diponogoro.

Hamdani. (2011). Strategi Belajar Mengajar. Bandung: Pustaka Setia.

Hermawan, Agus. (2013). Komunikasi Pemasaran. Jakarta: Erlangga.

Kotler, dan Keller. (2012). Manajemen Pemasaran, Edisi 12. Jakarta: Erlangga.

Kotler, Philip dan Keller. (2007). Manajemen Pemasaran, Jilid I, Edisi Kedua belas. Jakarta: PT. Indeks.

Kotler, Philip; Armstrong, Garry. (2008). Prinsipprinsip Pemasaran, Jilid 1. Jakarta: Erlangga. . (2012). Principles of Marketing. New Jersey: Prentice Hall.

Latief, Fitriani dan Dirwan. (2020). Pengaruh Kemudahan, Promosi Dan Kemanfaatan Terhadap Keputusan Penggunaan Uang Digital. Jurnal Ilmiah Akuntansi Manajemen Vol. 3 No.1.

Nitisusastro, Mulyadi. (2012). Perilaku Konsumen dalam Perspektif Kewirausahaan. Bandung: Alfabeta.

Permana, I.D. (2017). Pengaruh Promosi Terhadap Keputusan Pembelian Produk Lantai Kayu dan Pintu PT. Piji Di Jawa Timur. Jurnal Manajemen dan Start-Up Bisnis. Volume 2,
No.1.

Philip Kotler dan Kevin Lane Keller. (2008). Manajemen Pemasaran Ed 13, Jilid 1. Jakarta: Erlangga.

Prasetijo, R dan Ihalauw, J (2005). Perilaku Konsumen. Yogyakarta: Andi Offset.

Priyatno Duwi. (2016). SPSS Handbook. Yogyakarta: Media Kom.

Sangadji, E.M., dan Sopiah. (2013). Prilaku Konsumen: Pendekatan Praktis Disertai : Himpunan Jurnal Penelitian. Yogyakarta: Penerbit Andi.

Sari,M.A, Rodiana Listiawati, Novitasari \& Rahmanita Vidyasari. (2018). Analisa Pengaruh Daya Tarik Promosi, Persepsi Kemudahan, Persepsi Manfaat, Persepsi Keamanan Terhadap Minat Penggunaan E-Wallet (Studi Kasus Produk Gopay dan Link aja Pada Masyarakat Pengguna di Wilayah Jabodetabek). Jurnal Ekonomi dan Bisnis Vol.18 No. 2, Hal: 126-134.

Schiffman, L.G., \& Kanuk, L.L. (2010). Consumer Behaviour (10th ed). New Jersey: Pearson Prentice Hall.

Klub Basket Satria Indonesia Tangerang Selatan. Jurnal Pemasaran Kompetitif, Vol. 3, No. 3.

Sugiyono. (2010). Metode Penelitian Pendidikan Pendekatan Kuantitatif, Kualitatif, dan R\&D. Bandung: Alfabeta.

(2011). Metode Penelitian Kuantitatif, Kualitatif dan R\&D. Bandung: Afabeta.

(2012). Statistik Untuk Metode Penelitian Bisnis Edisi 10. Bandung: Afabeta. (2014). Metode Penelitian Pendidikan Pendekatan Kuantitatif, Kualitatif, dan R \& $D$. Bandung: Alfabeta.

Tjiptono, Fandy. (2010). Strategi Pemasaran, Edisi 2. Yogyakarta: Andi Offset.

https://inet.detik.com/cyberlife/d-3496233/ mayoritas-pengguna-go-jek-perempuansingle. 